\title{
Molecular Switches in the Development and Fate Specification of Vomeronasal Neurons
}

\author{
Rodrigo Suárez \\ The University of Queensland, Queensland Brain Institute, Brisbane QLD 4072, Australia \\ Review of Enomoto et al.
}

In mammals, social and sexual interactions are largely mediated by semiochemicals, traditionally known as pheromones, perceived by the vomeronasal system. The vomeronasal organ (VNO) sits at the base of the nasal septum and contains two populations of sensory neurons, segregated in apical and basal territories, that send axons to glomeruli of the rostral and caudal portion of the accessory olfactory bulb $(\mathrm{AOB})$, respectively (Halpern and MartínezMarcos, 2003). Apical neurons express V1 receptors, which associate with the $\alpha_{\mathrm{i} 2}$ subunit of G-protein $\left(\mathrm{G} \alpha_{\mathrm{i} 2}\right)$, whereas basal neurons express V2 receptors that associate with $\mathrm{G} \alpha$ o protein. The sensory profiles of the two populations differ in the size and the ethological specificity of their ligands. V1r-expressing neurons are largely sensitive to small lipophilic molecules, whereas V2r-expressing neurons respond primarily to peptides (Leinders-Zufall et al., 2000, 2009). Also, while individual V1r-neurons respond to scents from multiple, even contrasting, ethological contexts, such as conspecific, predatory, and nonpredatory semiochemicals, V2r-expressing neurons are mostly activated by compounds from a single ethological category, such as scents

Received Sept. 13, 2011; revised 0ct. 23, 2011; accepted 0ct. 24, 2011.

R.S. is supported by a postdoctoral fellowship from The University of Queensland.

Correspondence should be addressed to Rodrigo Suárez, Queensland Brain Institute, Building 79, St Lucia Campus, QLD 4072, Australia. E-mail: rsuarezsaa@gmail.com.

DOI:10.1523/JNEUROSCI.4682-11.2011

Copyright $\odot 2011$ the authors $\quad 0270-6474 / 11 / 3117761-03 \$ 15.00 / 0$ from a predator or a male or a female conspecific (Isogai et al., 2011).

Similar to main olfactory neurons, newborn vomeronasal neurons are constantly incorporated into functional circuits throughout ontogeny. However, the subcellular mechanisms guiding differentiation and incorporation of newborn neurons are incompletely understood.

Previous evidence has suggested a role of axon guidance molecules in the segregation of vomeronasal axons into their final position in the AOB (Knöll et al., 2001, 2003; Walz et al., 2002; Prince et al., 2009), but until recently, no study had proposed molecular candidates for the regulation of maturation and fate choice of newly generated vomeronasal neurons. In a recent article published in The Journal of Neuroscience, however, Enomoto et al. (2011) showed that Bcl11b/Ctip2, a zinc finger transcription factor involved in regulating corticofugal fate of deep-layered neocortical neurons (McKenna et al., 2011), is crucial for maturation and fate determination of vomeronasal neurons, for establishing axonal projections to the $\mathrm{AOB}$, and for correct layering of intrinsic $\mathrm{AOB}$ neurons.

By analyzing gene expression at different developmental stages, Enomoto et al. (2011) identify a sequence of events that occur during vomeronasal neuron maturation. They found that during embryogenesis, Bcl11b/Ctip2 is expressed in most terminal differentiating/immature vomeronasal neurons, whereas in adults, its expres- sion becomes restricted to the neurogenic niches of the marginal regions of the VNO. In the AOB, however, Bcl11b/Ctip2 is expressed in mature projecting neurons and interneurons, even during adulthood.

To further investigate the role of Bcl11b/ Ctip2 during vomeronasal neuron development, Enomoto et al. (2011) knocked out Bcl11b/Ctip2 and compared the expression of several markers of neuronal developmental stages in mutant and wild-type animals. In Bcl11b/Ctip $2^{-1-}$ mice, cell proliferation proceeded normally but differentiation was arrested in postmitotic neurons (Enomoto et al., 2011, their Fig. 5). Expression of Bcl11b/Ctip2 in wild-type mice was colocalized with markers of neuronal precursors (Ngn1 and NeuroD) and a marker of postmitotic immature neurons (SCG10), but not with a marker of early progenitors (Mash1).

Although Bcl11b/Ctip $2^{-1-}$ mice died soon after birth, their phenotypic development could be followed up to postnatal day 0 (P0). Until then, vomeronasal neurons showed no difference in cell number or organization between wild-type and knock-out mice. In contrast, the $\mathrm{AOB}$ showed a drastic reduction in vomeronasal projections and an aberrant cellular stratification. This suggests that Bcl11b/ Ctip2 regulates not only the maturation of vomeronasal neurons and their axonal pathfinding but also the formation of intrinsic AOB circuitry. Furthermore, Bcl11b/Ctip2 $2^{-1-}$ mice showed selective death of immature but not mature neurons, raising the question of whether cell death is 
A

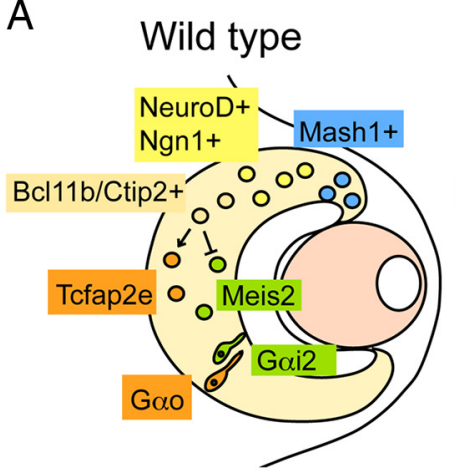

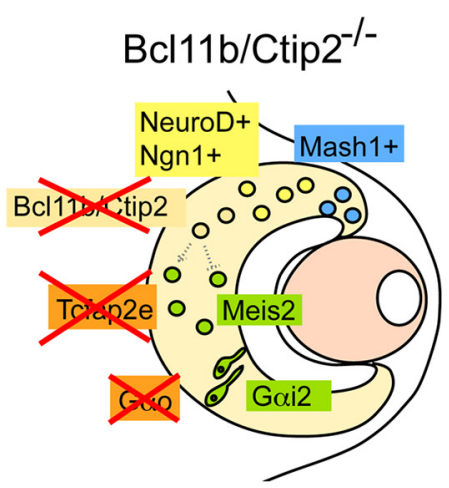

B

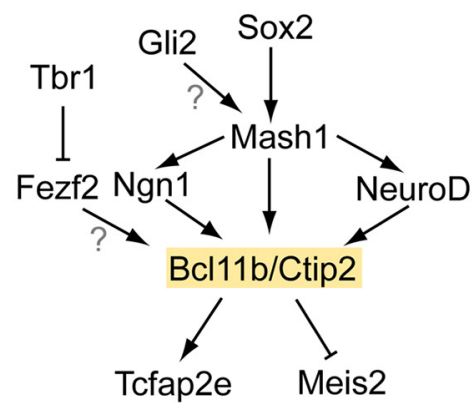

Gao-pathway Gai2-pathway

Figure 1. Molecular switches in vomeronasal maturation and fate determination. $\boldsymbol{A}$, Molecules involved in the maturation of vomeronasal neurons and fate determination. In wild-type mice (left), Mash1-expressing neurons are generated in the marginal zone of the vomeronasal organ and progressively express NeuroD, Ngn1, and Bcl11b/Ctip2, which in turn may activate Tcfap2e, a marker of basal neurons and/or inhibit Meis2, a marker of apical neurons. In Bcl11b/Ctip2 ${ }^{-1-}$ mice (right), few neurons express Tcfap2e and no neurons exclusively express $\mathrm{G} \alpha_{0}$. $\boldsymbol{B}$, Tentative scheme of molecules that may act upon $\mathrm{BCl11b/Ctip2} \mathrm{either} \mathrm{directly} \mathrm{or} \mathrm{indirectly.} \mathrm{See} \mathrm{text} \mathrm{for} \mathrm{references} \mathrm{regarding} \mathrm{each} \mathrm{interaction.}$

prevented in neurons whose axons have reached their final target at the AOB.

Given the regulatory nature of Bcl11b/ Ctip2 as a transcription factor, Enomoto et al. (2011) used DNA microarrays to identify genes whose expression was affected in Bcll1 b/Ctip $2^{-1-}$ mice. Of several genes that showed altered expression levels in knock-out mice, two were of particular interest because they are exclusively expressed at either apical or basal subpopulations: Meis2 labeled apical vomeronasal neurons and was upregulated in Bcl11b/Ctip $2^{-1-}$ mice, and Tcfap2e was expressed in basal neurons and was downregulated in Bcl11b/Ctip $2^{-/-}$mice (Fig. $1 A)$. The differential regulation of these genes suggested a role for Bcl11b/Ctip2 in fate differentiation of newborn neurons into one of the two vomeronasal pathways.

In developing wild-type mice, both apical and basal populations of early neurons express $\mathrm{G} \alpha_{\mathrm{o}}$ protein, but only apical neurons coexpress $\mathrm{G} \alpha_{\mathrm{i} 2}$ with $\mathrm{G} \alpha_{\mathrm{o}}$. During postnatal development, all $\mathrm{G} \alpha_{\mathrm{i} 2}$-expressing neurons cease to coexpress $\mathrm{G} \alpha$; by adulthood, all mature neurons express only one of the two G-proteins. In developing Bcl11b/ Ctip $2^{-1-}$ mice, however, the number of neurons that coexpressed both G-proteins was significantly higher and the number of neurons that only expressed $\mathrm{G} \alpha_{\mathrm{o}}$ was significantly lower than in wild-types (Enomoto et al., 2011, their Fig. 9). Interestingly, neurons that coexpressed $\mathrm{G} \alpha_{\mathrm{i} 2}$ and $\mathrm{G} \alpha_{\mathrm{o}}$ were not restricted to the apical region but were distributed throughout apical and basal areas. Enomoto et al. (2011) therefore proposed that $\mathrm{Bcl} 11 \mathrm{~b} / \mathrm{Ctip} 2$ regulates the phenotypic development of vomeronasal neurons by serving as a switch between $\mathrm{V} 1 \mathrm{r}-$ $\mathrm{G} \alpha_{\mathrm{i} 2}$ and $\mathrm{V} 2 \mathrm{r}-\mathrm{G} \alpha_{\mathrm{o}}$ fates (Enomoto et al., 2011, their Fig. 10).
What other molecules might be involved in this regulatory process? Evidence from neocortical development suggests that Bcl11b/Ctip2 plays an important role in the regulation of corticothalamic and corticospinal neuronal fates by responding differently to activators, such as Fezf2, and inhibitors, such as Tbr1 and Satb2 (McKenna et al., 2011). Indeed, Fezf2 has been recently described as an important component in specifying vomeronasal versus main olfactory fate, being selectively expressed in vomeronasal precursor cells as early as E10.5 (Eckler et al., 2011). Enomoto et al. (2011) show that Bcl11b/Ctip2 is under control of Mash1, an early marker of neuronal progenitors, by showing it is not expressed in $\mathrm{Mash}^{-1-} \mathrm{KO}$ mice. Interestingly, Kim et al. (2011) reported that Mash1 is not only expressed in transit-amplifying cell populations but also in long-term neurogenic niches such as the dentate gyrus of the hippocampus and the subventricular zone (Kim et al., 2011). One candidate molecule that might regulate Mash1 in the vomeronasal system is Sox2 (Gokoffski et al., 2010), which is expressed in stem cells of the main olfactory epithelium and is thought to participate in fate determination of olfactory neurons by activation of Mash 1 followed by Ngn1. Also, the Sonic Hedgehog signaling pathway might participate in the regulation of vomeronasal neurogenesis, as in vitro assays show direct binding of Gli2 protein to regions of the Mash1 gene to upregulate expression levels of Ngn1 and NeuroD (Voronova et al., 2011) (Fig. 1B).

In conclusion, the experiments by Enomoto et al. (2011) presented Bcl11b/ Ctip2 as a novel element of a system involved in the maturation and fate determination of vomeronasal neurons. They showed the sequential expression of genes that may be used in future studies as markers of developmental stages and they discovered two novel genes with selective expression in apical or basal territories as additional markers of the dichotomous vomeronasal pathways. Future experiments involving temporal- and cell-specific genetic manipulations will be of enormous help to better understand the maturation, fate choice, and circuit integration of newly generated vomeronasal neurons.

\section{References}

Eckler MJ, McKenna WL, Taghvaei S, McConnell SK, Chen B (2011) Fezf1 and Fezf2 are required for olfactory development and sensory neuron identity. J Comp Neurol 519:18291846.

Enomoto T, Ohmoto M, Iwata T, Uno A, Saitou M, Yamaguchi T, Kominami R, Matsumoto I, Hirota J (2011) Bcl11b/Ctip2 controls the differentiation of vomeronasal sensory neurons in mice. J Neurosci 31:10159-10173.

Gokoffski KK, Kawauchi S, Wu HH, Santos R, Hollenbeck PLW, Lander AD, Calof AL (2010) Feedback regulation of neurogenesis in the mammalian olfactory epithelium: new insights from genetics and systems biology. In: The neurobiology of olfaction (Menini A, ed.), pp 241-266. Boca Raton, FL: CRC.

Halpern M, Martínez-Marcos A (2003) Structure and function of the vomeronasal system: an update. Prog Neurobiol 70:245-318.

Isogai Y, Si S, Pont-Lezica L, Tan T, Kapoor V, Murthy VN, Dulac C (2011) Molecular organization of vomeronasal chemoreception. Nature 478:241-245.

Kim EJ, Ables JL, Dickel LK, Eisch AJ, Johnson JE (2011) Ascl1 (Mash1) defines cells with longterm neurogenic potential in subgranular and subventricular zones in adult mouse brain. PLoS One 6:e18472.

Knöll B, Zarbalis K, Wurst W, Drescher U (2001) A rolefor the EphA family in the topographic targeting of vomeronasal axons. Development 128:895-906.

Knöll B, Schmidt H, Andrews W, Guthrie S, Pini A, Sundaresan V, Drescher U (2003) On the 
topographic targeting of basal vomeronasal axons through Slit-mediated chemorepulsion. Development 130:5073-5082.

Leinders-Zufall T, Lane AP, Puche AC, Ma W, Novotny MV, Shipley MT, Zufall F (2000) Ultrasensitive pheromone detection by mammalian vomeronasal neurons. Nature 405:792796.

Leinders-Zufall T, Ishii T, Mombaerts P, Zufall F, Boehm T (2009) Structural requirements for the activation of vomeronasal sensory neurons by MHC peptides. Nat Neurosci 12:1551-1558.

McKenna WL, Betancourt J, Larkin KA, Abrams B, Guo C, Rubenstein JL, Chen B (2011) Tbr1 and Fezf2 regulate alternate corticofugal neuronal identities during neocortical development. J Neurosci 31:549-564.

Prince JE, Cho JH, Dumontier E, Andrews W, Cutforth T, Tessier-Lavigne M, Parnavelas J, Cloutier JF (2009) Robo-2 controls the segregation of a portion of basal vomeronasal sensory neuron axons to the posterior region of the accessory olfactory bulb. J Neurosci 29:14211-14222.

Voronova A, Fischer A, Ryan T, Al Madhoun A, Skerjanc IS (2011) Ascll/Mash1 is a novel target of Gli2 during Gli2-induced neurogenesis in P19 EC cells. PLoS One 6:e19174.

Walz A, Rodriguez I, Mombaerts P (2002) Aberrant sensory innervation of the olfactory bulb in neuropilin-2 mutant mice. J Neurosci 22: 4025-4035. 